http://jmscr.igmpublication.org/home/ ISSN (e)-2347-176x ISSN (p) 2455-0450

crossref DOI: https://dx.doi.org/10.18535/jmscr/v8i1.113

\title{
Outcome of Surgically Managed Ruptured Anterior Communicating Artery Aneurysms- An Observational Study
}

\author{
Authors \\ Jyothish L.S ${ }^{1}$, Varun Singh Pendro ${ }^{2 *}$, Jijo Joseph joseph ${ }^{3}$, Anilkumar P. ${ }^{4}$, \\ Rajmohan B.P.5 \\ ${ }^{1}$ Additional Professor, Dept. of Neurosurgery, ${ }^{2,3}$ Senior Resident, Dept. of Neurosurgery \\ ${ }^{4}$ Professor HOD, Dept. of Neurosurgery, ${ }^{5}$ Professor, Dept. of Neurosurgery \\ *Corresponding Author \\ Varun Singh Pendro
}

\begin{abstract}
The purpose of this retrospective study was to investigate outcome predictors for patients of ruptured anterior communicating artery aneurysm. In this study patients with ruptured anterior communicating artery aneurysm managed by surgery in this single institute from January 2011 to June 2017 were included. A uniform management protocol was adopted which included early surgery, post op ICU care and aggressive anti vasospasm treatment.

Methods: Retrospectively data of 124 patients was collected and reviewed. The patients were graded according to WFNS and Modified Fischer scoring, size of aneurysm, projections and outcomes were assessed at the time of discharge and after 3 months on the basis of modified Rankin scale.

Conclusion: This study demonstrated that preoperative score and postoperative Hydrocephalus are the factors determining outcome in patients with ruptured anterior communicating artery aneurysm.

Keywords: Aneurysm, Ruptured Anterior communicating artery aneurysm, Modified Rankin scale, Outcome.
\end{abstract}

\section{Introduction}

Anterior communicating (Acom) artery is the most common site, accounting for $20 \%$ of all intra cranial aneurysms in most of the large surgical and endovascular series 1,2,3,4,5,6,20. Aneurysms in this location have a higher risk of rupture than those in other locations ${ }^{6,7}$. The incidence of Acom aneurysms are significantly lower among unruptured intracranial aneurysms compared to its incidence among aneurysms presenting with subarachnoid hemorrhage ${ }^{8}$. These aneurysms have a high annual rate of rupture even when they are very small $^{7,9}$.
Unlike Western and Japanese literature, only few studies have been published describing the demography and epidemiology of this commonest type of intracranial aneurysm in Indian population.

The purpose of this study is to review the epidemiology of ruptured anterior communicating aneurysms, in terms of age, gender, size, projection, associated risk factors etc. in Indian population and to study the surgical outcome of these patients presenting with different clinical grades. 
By the turn of this century, endovascular coiling has become a safe alternative to surgical clipping. Most studies prove that it has lower morbidity than surgical clipping, both for ruptured and unruptured aneurysms $^{10,11,12}$. However there is a slightly higher incidence of aneurysm recurrence and rebleeding in endovascularly treated patients when compared to those treated by surgical clipping $^{10,11,12,13}$.

Advancement in the endovascular techniques have led to an increased proportion of Acom aneurysms being treated by this method. ${ }^{15,16}$

Very small Acom aneurysms are found to have an increased incidence of intraoperative rupture during endovascular clipping compared to aneurysms larger than $4 \mathrm{~mm}^{17}$. The projection of aneurysm is also may influence the choice of treatment. Anteriorly directed aneurysms are suitable for surgical clipping and posteriorly projecting ones, for endovascular coiling ${ }^{18}$.

Even though the duration of hospital stay is shorter in cases of unruptured aneurysms, the costs of treatment of both ruptured and unruptured aneurysms are higher for endovascular coiling when compared to surgical clipping. This is mainly because of the higher device cost for the coils than the clips. The advantages of the coiling over clipping will become beneficial to more patients only when the cost of coils are reduced significantly and becomes comparable with that of clips $^{19}$.

Even now in Indian scenario surgical clipping remains the mainstay of treatment for treatment of anterior circulation aneurysms because of the higher cost of treatment associated with the endovascular treatment ${ }^{14}$.

The study was approved by Institutional Review Board of Government Medical College (Constituted under State Board of Medical research). We retrospectively reviewed our departmental data base and medical records to identify and include in our study consecutive patients who presented with SAH caused by Acom Artery aneurysm rupture and were treated by surgical clipping between January 2011 and
June 2017. We conducted a meticulous review of demographic data, clinical parameters, neuroimaging studies, management, and shortterm as well as long-term outcomes in the young adult subgroup.

\section{Materials and Methods}

This observational study approved by Institutional review board is based on retrospective collection of data from patients who underwent craniotomy and clipping of Acom aneurysms from 01/01/2011 to $30 / 06 / 2017$ in Department of Neurosurgery, Government Medical College, Trivandrum. The data used in this study was collected from the medical records of the hospital. A total of 124 patients who were operated for A Com Artery Aneurysm were included in study. Patients of other aneurysm and patients managed conservatively were not included in study. SAH was initially diagnosed by brain computed tomography, and CT Cerebral angiography was followed. SAH was confirmed to be due to cerebral aneurysm. Location and features of cerebral aneurysm were confirmed.

The baseline demographic and clinical data included age; gender; World Federation of Neurological Surgeons (WFNS) grade at admission, concomitant diseases/risk factors, smoking, alcohol, Fisher grade at initial CT scan; size of aneurysm; projection of aneurysm, postoperative complications, hydrocephalus. Modified rank in scale (MRS) were all analyzed at the time of discharge and 3 months after discharge. The prognostic study was derived from an analysis of these variables.

All patients included in the study underwent appropriate standard craniotomy and clipping of aneurysm. Post operatively all patients were admitted to the neurosurgical intensive care unit, and almost all underwent triple $\mathrm{H}$ therapy (hypervolemia, hypertension and hemodilution) to maintain central venous pressure at the level of 10 $\mathrm{cm} \mathrm{H} 2 \mathrm{O}$ and systolic blood pressure above 150 $\mathrm{mmHg}$. Tab Nimodipine was administered orally or via nasogastric tube in intubated patients for 
three weeks to prevent vasospasm in the postoperative period. Anticonvulsants were routinely administered in the preoperative and postoperative periods.

Statistical analysis was performed using SPSS software (SPSS Inc., Chicago, Illinois, USA). All data are presented as mean values \pm standard deviation. The demographic distribution of the patients in the study and the clinical and prognostic parameters were tabulated. Uni- and multivariate predictors of the outcome based on the MRS were assessed using binary logistic regression analysis. Odds ratio and 95\% confidence intervals were computed. The correlation between the significant predictors of the outcome and the long-term MRS was analyzed using a multivariate logistic regression analysis. A probability value $(p<0.05)$ was considered significant.

\section{Result}

This study was conducted in Department of neurosurgery, Government Medical College, Trivandrum. A total of 124 patients who were operated for A Com Artery Aneurysm from 01/01/2011 to 30/06/2017 were included in study. All patients' data were summarized in Tables I- II. The age, gender, World Federation of Neurological Surgeons (WFNS) grade at admission, concomitant diseases (Hypertension, Diabetes mellitus), smoking, alcohol, Modified Fisher grade at initial CT scan, size of aneurysm, projection of aneurysm, postoperative hydrocephalus were evaluated. WFNS grade $(\mathrm{P}<0.001)$, Modified Fisher grade at initial CT scan $(\mathrm{P}<0.001)$ and Hydrocephalus $\mathrm{p}<0.008)$ were found to be independent risk factor for outcome. The Multivariate effects of other variables were not significant.

Table 1: Results obtained

\begin{tabular}{|c|c|c|}
\hline Age (years) & Min-Max & $17-80$ \\
\hline & Mean +- SD & $53.55+-10.25$ \\
\hline & $<40$ & $11(8.9 \%)$ \\
\hline & $41-45$ & $16(12.9 \%)$ \\
\hline & $46-50$ & $15(12.1 \%)$ \\
\hline & $51-55$ & $27(21.8 \%)$ \\
\hline & $56-60$ & $26(21 \%)$ \\
\hline & $61-65$ & $22(17.7 \%)$ \\
\hline & $66-70$ & $4(3.2 \%)$ \\
\hline & $>70$ & $3(2.4 \%)$ \\
\hline \multirow[t]{2}{*}{ Sex } & Male & $76(61 \%)$ \\
\hline & Female & $48(38.7)$ \\
\hline Hypertension & $\mathrm{N}$ & $53(42.7 \%)$ \\
\hline DM & $\mathrm{N}$ & $13(10.5 \%)$ \\
\hline Smoking & $\mathrm{N}$ & $26(21 \%)$ \\
\hline Alcohol & $\mathrm{N}$ & $22(17.7 \%)$ \\
\hline \multirow[t]{4}{*}{ WFNS } & Grade 1 & $77(62.1 \%)$ \\
\hline & Grade 2 & $23(18.5 \%)$ \\
\hline & Grade 3 & $11(8.9 \%)$ \\
\hline & Grade 4 & $13(10.5 \%)$ \\
\hline \multirow[t]{5}{*}{ Modified FISCHER } & Grade 0 & $1(0.8 \%)$ \\
\hline & Grade 1 & $68(54.8 \%)$ \\
\hline & Grade 2 & $17(13.7 \%)$ \\
\hline & Grade 3 & $16(12.9 \%)$ \\
\hline & Grade 4 & $22(17.7 \%)$ \\
\hline \multirow[t]{4}{*}{ Projection } & Anterior & $56(45.2 \%)$ \\
\hline & Superior & $35(28.2 \%)$ \\
\hline & Inferior & $25(20.2 \%)$ \\
\hline & Posterior & $8(6.4 \%)$ \\
\hline \multirow[t]{4}{*}{ Size } & $<5 \mathrm{~mm}$ & $26(21 \%)$ \\
\hline & $6-10 \mathrm{~mm}$ & $82(66.1 \%)$ \\
\hline & $11-15 \mathrm{~mm}$ & $15(12.1 \%)$ \\
\hline & $16-20 \mathrm{~mm}$ & $1(0.8 \%)$ \\
\hline Hydrocephalus & $\mathrm{N}$ & $44(35 \%)$ \\
\hline
\end{tabular}


Table 2 Evaluation of Parameters according to Outcome

\begin{tabular}{|c|c|c|c|c|}
\hline Age (years) & & Good Outcome $(\mathrm{n}=91)$ & Poor Outcome $(n=33)$ & $\mathrm{p}$ \\
\hline & $<40$ & $11(12.1 \%)$ & 0 & \multirow[t]{8}{*}{$\mathrm{P}=0.303$} \\
\hline & $41-45$ & $12(13.1 \%)$ & $4(12.1 \%)$ & \\
\hline & $46-50$ & $10(11 \%)$ & $5(15.2 \%)$ & \\
\hline & $51-55$ & $20(22 \%)$ & $7(21.2 \%)$ & \\
\hline & $56-60$ & $18(19.8 \%)$ & $8(24.2 \%)$ & \\
\hline & $61-65$ & $17(18.7 \%)$ & $5(15.2 \%)$ & \\
\hline & $66-70$ & $2(2.2 \%)$ & $2(6.1 \%)$ & \\
\hline & $>70$ & $1(1.1 \%)$ & $2(6.1 \%)$ & \\
\hline \multirow[t]{2}{*}{ Sex } & Male & $55(60.4 \%)$ & $21(63.6 \%)$ & \multirow[t]{2}{*}{$\mathrm{P}=0.747$} \\
\hline & Female & $36(39.6 \%)$ & $12(36.4 \%)$ & \\
\hline Hypertension & $\mathrm{N}=71$ & $54(59.3 \%)$ & $17(51.5 \%)$ & $\mathrm{P}=0.436$ \\
\hline DM & $\mathrm{N}=13$ & $7(7.7 \%)$ & $6(18.2 \%)$ & $\mathrm{P}=0.092$ \\
\hline Smoking & $\mathrm{N}=26$ & $18(19.8 \%)$ & $8(24.2 \%)$ & $\mathrm{P}=0.590$ \\
\hline Alcohol & $\mathrm{N}=22$ & $15(16.5 \%)$ & $7(21.2 \%)$ & $\mathrm{P}=0.542$ \\
\hline \multirow[t]{4}{*}{ WFNS } & Grade 1 & $66(72.5 \%)$ & $11(3.3 \%)$ & \multirow[t]{4}{*}{$\mathrm{P}<0.001$} \\
\hline & Grade 2 & $17(18.7 \%)$ & $6(18.2 \%)$ & \\
\hline & Grade 3 & $6(6.6 \%)$ & $5(15.2 \%)$ & \\
\hline & Grade 4 & $2(2.2 \%)$ & $11(33.3 \%)$ & \\
\hline \multirow[t]{5}{*}{ Modified FISCHER } & Grade 0 & $1(1.1 \%)$ & 0 & \multirow[t]{5}{*}{$\mathrm{P}<0.001$} \\
\hline & Grade 1 & $63(69.2 \%)$ & $5(15.2 \%)$ & \\
\hline & Grade 2 & $17(18.7 \%)$ & 0 & \\
\hline & Grade 3 & $6(6.6 \%)$ & $10(30.3 \%)$ & \\
\hline & Grade 4 & $4(4.4 \%)$ & $18(54.5 \%)$ & \\
\hline \multirow[t]{4}{*}{ Projection } & Anterior & $42(46.2 \%)$ & $14(42.4 \%)$ & \multirow[t]{4}{*}{$\mathrm{P}=0.162$} \\
\hline & Superior & $22(24.2 \%)$ & $13(39.4 \%)$ & \\
\hline & Inferior & $21(23.1 \%)$ & $4(12.1 \%)$ & \\
\hline & Posterior & $6(6.6 \%)$ & $2(6.1 \%)$ & \\
\hline \multirow[t]{4}{*}{ Size } & $<5 \mathrm{~mm}$ & $22(24.2 \%)$ & $4(12.1 \%)$ & \multirow[t]{4}{*}{$\mathrm{P}=0.319$} \\
\hline & 6-10 mm & $60(65.9 \%)$ & $22(66.7 \%)$ & \\
\hline & $11-15 \mathrm{~mm}$ & $8(8.8 \%)$ & $7(21.2 \%)$ & \\
\hline & $16-20 \mathrm{~mm}$ & $1(1.1 \%)$ & 0 & \\
\hline Hydrocephalus & $\mathrm{N}=44$ & $26(28.6 \%)$ & $18(54.5 \%)$ & $\mathrm{p}=0.008$ \\
\hline
\end{tabular}

\section{Discussion}

The rupture of a cerebral aneurysm is the most common cause of spontaneous subarachnoid haemorrhages. Despite improvements in its diagnosis and treatment, subarachnoid haemorrhages still continue to be associated with poor prognosis. Ruptured intracranial aneurysms are having high mortality and morbidity and the predictive factors of a poor prognosis remain unknown. The factors which are affecting the outcomes after ruptured intracranial aneurysm have been investigated in several studies. Age, Gender, history of hypertension, Diabetes mellitus, Admission WFNS grade, the presence of a clinical vasospasm, Fisher's grade, timing of surgery, intraoperative rupture, the development of hydrocephalus, time of admission after $\mathrm{SAH}$, aneurysm location and size, presence of intracerebral or intraventricular hemorrhage, and blood pressure at admission are among the prognostic factors that have been investigated, and some of these have gained worldwide acceptance, while controversy still exists regarding the others.

\section{Age \& Gender}

Age is an important factor which influences the outcome of patients, and caries an important prognostic value in the disease. A more advanced age indicates an unfavorable outcome ${ }^{(21-25,28)}$. Chotai et al found that in a univariate regression analysis of the outcomes at discharge that the age of the patient at the time of presentation and male gender were predictors of an unfavorable outcome. ${ }^{(26)}$ Schöller et al. ${ }^{(27)}$ reported that patients aged $<70$ years with an initial WFNS score of I-III showed the best clinical recovery rates. The outcome clearly worsened with increasing age, and age was one of the strongest predictors of mortality and a poor outcome. They showed that age itself contributes to a negative outcome, independent of the condition at admission and the presence of any pre-existing medical diseases. There are studies suggesting that age and sex have 
no prognostic value. ${ }^{(29-32)}$ In the present study, mean was 53.5 years and there was no statistically significant difference between age and genders in terms of Outcome according to modified Rankin scale.

\section{Risk Factors}

Hypertension, Diabetes mellitus, Alcoholism and Smoking were found to be major risk factors in the development and rupture of cerebral aneurysms, although there is a lack of agreement as to whether they are prognostic factors in outcome $^{(24,33)}$. Based on a multivariate exact regression analysis, hypertension was found to be a predictor of outcome at a mean two-year follow up $^{(26)}$. Raised blood pressure and the pre-existing medical illness are predictive of mortality ${ }^{(23)}$. Disney et al. ${ }^{(22)}$ reported that initial systolic blood pressure had relative importance as a prognostic factor in outcomes, although other authors claim that a history of essential arterial hypertension is not related to outcome ${ }^{(30-32)}$. In the study by Ohman et al. ${ }^{(34)}$ a history of hypertension was reported to be a prognostic factor for cerebral infarction in patients after aneurysmal SAH. The overall rate of risk factors, including hypertension (42.7\%), diabetes mellitus (10.5\%), alcohol $(17.7 \%)$ and smoking $(21 \%)$ was present in our patients. Hypertension was found to be the most common reported preexisting illness $(42.7 \%)$. We found no statistically significant difference between the outcome in terms of Modified rankin scale.

\section{Size}

Chotai et al. ${ }^{(26)}$ found that the size of the aneurysm is associated with unfavourable outcomes. Shiue et al. (35) also point out that the size of a ruptured aneurysm is an important determinant of outcome in $\mathrm{SAH}$, and should be used as a prognostic parameter in directing management. An aneurysm larger than $10 \mathrm{~mm}$ is associated with a poorer progression, and size had relative importance as a prognostic factor for outcome ${ }^{(22,36)}$. Similar to other studies, in the logistic regression analysis, an aneurysm size above $7 \mathrm{~mm}$ was found to be an independent risk factor for postoperative outcome.
In our study we detected maximum aneurysm were of size $6-10 \mathrm{~mm} 82(66.1 \%)$ and there was no statistical difference in outcome.

\section{Fisher Grade}

A high Fisher grade indicates has been widely accepted as an important factor for a poor prognosis ${ }^{(28,30,32,36)}$. The amount of blood in the subarachnoid space correlates to the occurrence of vasospasms. The thickness of blood clots identified and measured during CT scans can be considered a valuable predictor of outcome ${ }^{(34,37,38)}$. High Fisher grade, Large intracranial hematoma volume and Large amount of intraventricular hemorrhage have all been associated to poor outcomes $^{(39)}$. In multivariate analysis the amount of extravascular blood and that of clinical grade were reported as independent prognostic factors of symptomatic vasospasm occurrence ${ }^{(40)}$. In contrast, Jamjoom et al. ${ }^{(31)}$ reported that intraventricular blood in $\mathrm{CT}$ and the presence of subarachnoid did not reach a statistical significance. Poor outcome was found to be significantly higher among patients with Fisher Grade III and IV in our cases.

\section{World Federation of Neurologic Surgeons Grade}

A poor pre-operative WFNS and Hunt and Hess scores is associated with an unfavorable outcome. Level of consciousness has been regarded as one of the major factors of outcome after an aneurysmal SAH. Although the level of consciousness is a major determinant of outcome after subarachnoid hemorrhage, there is a lack of consensus on which classification should be used to define it. The WFNS grading scale was failed to predict significant differences in outcome across various grades $^{(25)}$.

Patient age, size of aneurysm, severity of subarachnoid hemorrhage (Modified Fisher grading), and clinical condition (Hunt and Hess grade) were each independently and strongly associated with long-term outcome. We found that the WFNS grade was significantly higher among the patient with poor outcome. In a logistic 
regression analysis, a high WFNS grade was found to be an independent risk factor.

\section{References}

1. Hernesniemi J, Dashti R, Lehecka M, et al. Microneurosurgical management of anterior communicating artery aneurysms. Surg Neurol 2008;70:8-28

2. Kassell NF, Torner JC, Haley EC Jr, Jane JA, Adams HP, Kongable GL. The International Cooperative Study on the Timing of Aneurysm Surgery. Part 1: Overall management results. J Neurosurg. 3(1): 8-36; 1990.

3. Zhao L, Zhang L, Zhang X, Li Z, Tian L, et al. (2014) An Analysis of 1256 Cases of Sporadic Ruptured Cerebral Aneurysm in a Single Chinese Institution. PLoS ONE 9(1): e85668. doi:10.1371/journal.pone.0085668

4. Molyneux AJ, Kerr RS, Yu LM, Clarke M, Sneade M, Yarnold JA, et al. International subarachnoid aneurysm trial (ISAT) of neurosurgical clipping versus endovascular coiling in 2143 patients with ruptured intracranial aneurysms: a randomised comparison of effects on survival, dependency, seizures, rebleeding, subgroups, and aneurysm occlusion. Lancet. 2005;366:809-817.

5. Riina HA, Lemole GM Jr, Spetzler RF. Anterior communicating artery aneurysms. Neurosurgery. 2002 Oct; 51(4):993-996.

6. Brisman JL, Song JK, Newell DW. Cerebral aneurysms. N Engl J Med 2006;355:928-39

7. Forget TR Jr, Benitez R, Veznedaroglu E, et al. A review of size and location of ruptured intracranial aneurysms. Neurosurgery 2001;49:1322-5; discussion 25-6.

8. Morita A, Kirino T, Hashi K, Aoki N, Fukuhara S, Hashimoto $\mathrm{N}$, et al. The natural course of unruptured cerebral aneurysms in a Japanese cohort. N Engl $\mathbf{J}$ Med. 2012;366:2474-2482.

9. Ohashi Y, Horikoshi T, Sugita M, Yagishita T, Nukui H. Size of cerebral aneurysms and related factors in patients with subarachnoid hemorrhage. Surg Neurol. 2004;61:239-245; discussion 245.

10. Kashiwazaki D, Kuroda S; Sapporo SAH Study Group. Size ratio can highly predict rupture risk in intracranial small $(<5 \mathrm{~mm})$ aneurysms. Stroke. 2013;44:2169-2173.

11. Molyneux AJ, Kerr RS, Birks J, Ramzi N, Yarnold J, Sneade M, et al. Risk of recurrent subarachnoid haemorrhage, death, or dependence and standardised mortality ratios after clipping or coiling of an intracranial aneurysm in the International Subarachnoid Aneurysm Trial (ISAT): long-term follow-up. Lancet Neurol. 2009;8:427-433

12. 12.Li H, Pan R, Wang H, et al. Clipping versus coiling for ruptured intracranial aneurysms: a systematic review and metaanalysis. Stroke 2013;44(1):29-37.

13. Raymond J, Guilbert F, Weill A, Georganos SA, Juravsky L, Lambert A, Lamoureux J, Chagnon M, Roy D. Longterm angiographic recurrences after selective endovascular treatment of aneurysms with detachable coils. Stroke. 2003;34:1398-1403.

14. Ambekar S, Madhugiri V, Pandey P, Yavagal DR. Cerebral aneurysm treatment in India: Results of a national survey regarding practice patterns in India. Neurol India 2016;64:62-9.

15. HuangQH,WuYF,XuY, et al. Vascular geometry change because of endovascular stent placement for anterior communicating artery aneurysms. AJNR Am J Neuroradiol 2011;32:1721-25

16. Cherian MP, Pranesh MB, Mehta P, et al. Outcomes of endovascular coiling of anterior communicating artery aneurysms in the early post-rupture period: a 
prospective analysis. Neurol India 2001;59:218-23

17. Schuette AJ, Hui FK, Spiotta AM, et al. Endovascular therapy of very small aneurysms of the anterior communicating artery: five-fold increased incidence of rupture. Neurosurgery 2011;68:731-37

18. Proust $\quad F^{1}$, Debono B, Hannequin $\mathrm{D}$, Gerardin E, Clavier E, Langlois O, Fréger $\mathrm{P}$ Treatment of anterior communicating artery aneurysms: complementary aspects of microsurgical and endovascular procedures. . J Neurosurg. 2003 Jul;99(1):3-14.

19. Hoh $\mathrm{BL}^{1}$, Chi YY, Dermott MA, Lipori PJ, Lewis SB. The effect of coiling versus clipping of ruptured and unruptured cerebral aneurysms on length of stay, hospital cost, hospital reimbursement, and surgeon reimbursement at the university of Florida.

Neurosurgery. 2009 Apr;64(4):614-9

20. Salas E, Ziyal IM, Bejjani GK, Sekhar LN. Anatomy of the frontotemporal branch of the facial nerve and indications for interfascial dissection. Neurosurgery 43(3): 563-568; 1998.

21. Bazowski P, Gamrot J, Rudnik A, Konopka M: Analysis of selected prognostic factors in patients with ruptured cerebral aneurysms operated-on in the early period. Neurol Neurochir Pol Suppl 1:25-28, 1992.

22. Disney L, Weir B, Grace M: Factors influencing the outcome of aneurysm rupture in poor grade patients: A prospective series. Neurosurgery 23:19,1988

23. Kassel NF, Torner JC, Haley EC, Jane JA, Adams HP, Kongable GL: The international cooperative study on the timing of aneurysm surgery, part 1: Overall management results. J Neurosurg 73:18-36, 1990
24. Kleinpeter G, Lehr S: Is hypertension a major risk factor in aneurysmal subarachnoid hemorrhage? Wien Klin Wochenschr 15:307-314, 2002

25. Lagares A, Gómez PA, Lobato RD, Alén JF, Alday R, Campollo J: Prognostic factors on hospital admission after spontaneous subarachnoid haemorrhage. Acta Neurochir (Wien) 143:665-672, 2001

26. Schöller K, Massmann M, Markl G, Kunz M, Fesl G, Brückmann H, Pfefferkorn T, Tonn JC, Schichor C: Aneurysmal subarachnoid hemorrhage in elderly patients: Long-term outcome and prognostic factors in an interdisciplinary treatment approach. J Neurol 260:10521060, 2013

27. Schöller K, Massmann M, Markl G, Kunz M, Fesl G, Brückmann H, Pfefferkorn T, Tonn JC, Schichor C: Aneurysmal subarachnoid hemorrhage in elderly patients: Long-term outcome and prognostic factors in an interdisciplinary treatment approach. J Neurol 260:10521060, 2013

28. Shimoda M, Oda S, Tsugane R, Sato O: Prognostic factors in delayed ischaemic deficit with vasospasm in patients undergoing early aneurysm surgery. $\mathrm{Br} \mathrm{J}$ Neurosurg 11:210-215, 1997

29. Bohnstedt BN, Nguyen HS, Kulwin CG, Shoja MM, Helbig GM, Leipzig TJ, Payner TD, Cohen-Gadol AA: Outcomes for clip ligation and hematoma evacuation associated with 102 patients with ruptured middle cerebral artery aneurysms. World Neurosurg 80:335-341, 2013

30. Gomis P, Rousseaux P, Jolly D, Graftieaux JP: Initial prognostic factors of aneurysmal subarachnoid hemorrhage. Neurochirurgie 40:18-30, 1994

31. Jamjoom A, Jamjoom ZA, Stranjalis G, Cummins B, Torrens M: The outcome of surgery of aneurysmal subarachnoid 
haemorrhage. Br J Clin Pract 47:136-140, 1993

32. Lin CL, Kwan AL, Howng SL: Surgical outcome of anterior communicating artery aneurysms. Kaohsiung J Med Sci 14:561568, 1998

33. Vlak MH, Rinkel GJ, Greebe P, Greving JP, Algra A: Lifetime risks for aneurysmal subarachnoid haemorrhage: Multivariable risk stratification. J Neurol Neurosurg Psychiatry 84:619-623, 2013

34. Ohman J, Servo A, Heiskanen O: Risks factors for cerebral infarction in goodgrade patients after aneurysmal subarachnoid hemorrhage and surgery: A prospective study. J Neurosurg 74:14- 20, 1991.

35. Shiue I, Arima H, Hankey GJ, Anderson CS: Location and size of ruptured intracranial aneurysm and serious clinical outcomes early after subarachnoid hemorrhage: A population-based study in Australasia. Cerebrovasc Dis 31:573-579, 2011

36. Pedraza S, Méndez-Méndez J: The prognostic value of computerized tomography in acute aneurysmal subarachnoid haemorrhages. Rev Neurol 39:359-363, 2004

37. Piazza P, Lisotto C, Querin F, Morassut S, Pomes A: Usefulness of computerized tomography in the prognosis of subarachnoid hemorrhage. Radiol Med 79:585-589, 1990

38. Rosen DS, Macdonald RL: Grading of subarachnoid hemorrhage: Modification of the world World Federation of Neurosurgical Societies scale on the basis of data for a large series of patients. Neurosurgery 54:566-575, 2004.
39. Lagares A, Gómez PA, Lobato RD, Alén JF, Alday R, Campollo J: Prognostic factors on hospital admission after spontaneous subarachnoid haemorrhage. Acta Neurochir (Wien) 143:665-672, 2001

40. Charpentier C, Audibert G, Guillemin F, Civit T, Ducrocq X, Bracard S, Hepner H, Picard L, Laxenaire MC: Multivariate analysis of predictors of cerebral vasospasm occurrence after aneurismal subarachnoid hemorrhage. Stroke 30:14021408, 1999

41. Alemán-Rivera A, Camacho-Gómez A: The results of surgical treatment in 100 patients operated on for intracranial aneurysms of the anterior circulation. Rev Neurol 32:1128-1131, 2001

42. Ostábal MI, Sanz C, Suárez MA, Salvo L, Millastre A: The study of prognostic factors of spontaneous subarachnoid hemorrhage. Rev Neurol 25:58-60, 1997

43. Rosen DS, Macdonald RL: Subarachnoid hemorrhage grading scales: A systematic review. Neurocrit Care 2:110-118, 2005. 